Articles by other investigators that follow this introduction include comorbidity with juvenile-onset mania (ADHD may signal a very early onset of bipolar disorder); two new subclassifications (1. ADHD plus comorbid anxiety disorder may predict a lesser response to MPH; 2) ADHD plus conduct disorder and aggressive behavior predicts a more negative outcome); gender differences (ADHD girls have greater intellectual impairment, lower levels of hyperactivity, and lower rates of aggression); benefits of parent-assisted social skills training (ADHD-peer rejection may be benefited by a combination of child social skills training, training for the parents, and stimulant medication). (Cantwell DP. Introduction. The scientific study of child and adolescent psychopathology: The attention deficit disorder syndrome. I Am Acad Child Adolesc Psychiatry Aug 1997;36:1033-1035). (Reprints: Dr James McCracken, UCLA NPI 48-270, 760 Westwood Plaza, Los Angeles, CA 90024).

COMMENT. Future research suggested by the articles in this excellent review include: 1 . The relation of MPH response to outcome over time; 2 . different diagnostic criteria based on gender and age; 3 . criteria for adult ADD; 4. genetic and biological markers; and 5. long-term efficacy of stimulant treatment. We should also add the need for research on adverse effects of stimulant therapy, including medication-induced seizures.

\title{
MEDICATION-INDUCED SEIZURES IN ADHD
}

The case of a 13-year-old boy with a history of ADHD and depressive disorder who had a tonic-clonic seizure 1 week after treatment with methylphenidate $(80 \mathrm{mg} /$ day $)$ and sertraline $(50 \mathrm{mg} /$ day $)$ is reported from Wright State University, School of Medicine, Dayton, OH. MPH dosage had been gradually increased over 1 year, and sertraline was added because of a worsening of depression. The seizure occurred one week after starting the combination therapy. The EEG was normal. Sertraline was discontinued, and $\mathrm{MPH}$ was continued unchanged with no recurrence of seizures. (Feeney DJ, Klykylo WM. Medication-induced seizures. (Letter to the Editor). I Am Acad Child Adolesc Psychiatry Aug 1997;36:1018-1019).

COMMENT. Methylphenidate alone may induce seizures in susceptible patients (see Ped Neur Briefs May 1997;p38), but the risk is aggravated by the addition of certain antidepressants. Despite the normal EEG in the above patient, it is probably advisable to order an EEG in a child with ADHD who requires a combination of stimulant and antidepressant medication. Epileptiform discharges in the EEG may prompt the addition of antiepileptic medication in some patients requiring treatment for $\mathrm{ADHD}$ and/or depression.

\section{SEIZURE DISORDERS}

\section{MOVEMENT-INDUCED SEIZURES}

Recurrent partial tonic postural seizures precipitated by slow movements unrelated to cognitive tasks are reported in a 16-year-old righthanded boy treated at Instituto di Clinica delle Malattie Nervose e Mentali, Rome, Italy. Performing repetitive flexion-extension of the right hand fingers, as in feeling coins in his pocket, induced a tonic posturing of the right arm followed by extension of the left hand and deviation of the head to the left. The ictal EEG showed brief voltage attenuation followed by $4-\mathrm{Hz}$ sharp wave discharge in frontal-central regions, maximal left. Interictal SPECT 
showed hypoperfusion in the right frontal-central area. Carbamazepine treatment had completely controlled seizures at 22 month follow-up. (Pierelli F, Di Gennaro G. Gherardi M, Spanedda F, Marciani MG. Epilepsia Aug 1997;38:941-944). (Reprints: Dr F Pierelli, Instituto di Clinica delle Malattie Nervose e Mentali, Viale dell'Universita 30, 00185, Rome, Italy).

COMMENT. Reflex seizures induced by movement have been reported previously, sometimes in patients with nonketotic hyperglycemia of diabetes mellitus.

\section{AGE-DEPENDENT STATUS EPILEPTICUS}

The records of 394 children aged 1 month to 16 years with status epilepticus (SE) were reviewed at the Montefiore Medical Center, Bronx, NY, and Medical College of Virginia, Richmond, VA. The mean age of onset was 4 years, and more than half the cases occurred under 3 years. Causes were agedependent. Febrile or acute symptomatic SE occurred at less than 2 years, whereas cryptogenic and remote symptomatic cases were common in older children. Prior neurologic abnormalities were noted in $40 \%$ ( $21 \%$ of younger and $55 \%$ of those older than 2 years), and a history of previous seizures in $45 \%$. The prevalence of previous seizures was significantly higher in older children; $64 \%$ in those older than 2 years and $20 \%$ in children less than 2 years. (Shinnar S, Pellock JM, Moshe SL et al. In whom does status epilepticus occur: Age-related differences in children. Epilepsia Aug 1997;38:907-914). (Reprints: Dr S Shinnar, Epilepsy Management Center, Montefiore Medical Center, $111 \mathrm{E}$ 210th St, Bronx, NY 10467).

COMMENT. Young children are particularly susceptible to status epilepticus, primarily those without neurologic abnormalities and with no previous unprovoked seizures. Older children with SE have a history of prior cryptogenic seizures, but are more frequently neurologically impaired.

\section{HERPES SIMPLEX VIRUS AND SURGICAL EPILEPSY}

The presence of herpes simplex virus (HSV) was determined by polymerase chain reaction in surgical specimens from 50 patients (13 to 58 years of age) with epilepsy obtained from multiple centers, including the National Neurological Research Specimen Bank, West Los Angeles Veterans Affairs Medical Center, Los Angeles, CA. Twenty (40\%) of the 50 epilepsy surgical cases and only $2(4 \%)$ of 48 control autopsy specimens from Alzheimer and Parkinson disease patients tested positive for HSV. Heterotopias were the most frequent epileptic tissue abnormalities (12 cases), and $67 \%$ tested positive for HIV. Of 8 with hippocampal sclerosis, $50 \%$ were HIV positive. (Sanders VJ, Felisan SL, Waddell AER et al. Presence of herpes simplex DNA in surgical tissue from human epileptic seizure foci detected by polymerase chain reaction. Arch Neurol Aug 1997;54:954-960). (Respond: Dr WW Tourtellotte, Neurology Services (127A), West Los Angeles VA Medical Center, 11301 Wilshire Blvd, Los Angeles, CA 90073).

COMMENT. Although this finding of herpes simplex virus in epileptogenic cerebral tissue does not prove a causative effect, the association is provocative and should stimulate research of possible viral etiology of refractory epilepsies in children, especially those with evidence of heterotopias, infantile spasms, complex febrile seizures, and perhaps, the Landau-Kleffner syndrome. A trial of acyclovir may be considered in some. 